\title{
Perioperative care of the cocaine-dependent neurosurgical patient
}

\author{
Sanjay Dwarakanath ${ }^{2}$, Aaron M. Cook ${ }^{3}$ and Brenda G. Fahy ${ }^{1 *}$ \\ ${ }^{*}$ Correspondence: bfahy@anest.ufl.edu \\ 'Department of Anesthesiology, College of Medicine, University of Florida, Gainesville, FL, USA. \\ 2Department of Anesthesiology, University of Kentucky, Lexington, KY, USA. \\ ${ }^{3}$ Pharmacy Specialist-Neurosurgery/Critical Care, Assistant Adjunct Professor, Pharmacy UK Healthcare, USA.
}

\begin{abstract}
Purpose: Cocaine, a commonly abused drug, can cause life-threatening complications, significantly impacting patient management. Cocaine is associated with an increased risk of stroke including subarachnoid hemorrhage (SAH) that may require expectant surgical management. Patients presenting for anesthesia with acute cocaine toxicity pose additional concerns.

Clinical Features: A 48 year old woman presented with a seizure, acute cocaine intoxication, and was diagnosed with a SAH. Further diagnostic evaluation revealed a bleeding cerebral aneurysm requiring urgent surgical aneurysm clipping. Her perioperative course was complicated by hypertension requiring treatment to minimize further aneurysm bleeding before clipping. Cocaine-associated cardiac complications impacting management included a non-ST elevation myocardial infarction and severe anteroseptal hypokinesis on echocardiogram.

Conclusion: Hemodynamic management with a recent SAH and acute cocaine intoxication required special considerations. Perioperative SAH management initially focused to prevent additional bleeding before clipping and then after clipping to minimize cerebral ischemia. Benzodiazepines were used early in this case to treat seizures and cocaine-associated hemodynamic effects. Specific treatments for life-threatening ventricular arrhythmias are discussed including sodium bicarbonate as a first line treatment and potential benefits of magnesium administration. With prolongation of a QT interval secondary to cocaine and/ or SAH, medications that often are utilized during the perioperative period may further prolong the QT interval and should be avoided.
\end{abstract}

Keywords: SAH, anaesthetic management, perioperative care, cocaine use

\section{Introduction}

Cocaine is the most commonly abused drug among patients presenting to hospital emergency departments [1] and the one most associated with drug-related mortalities [2]. Cocaine is a common illicit drug with the highest prevalence rate in North American and an estimated 14 million cocaine users (ages 1564 years) worldwide [3]. Cocaine is associated with a higher risk of stroke [4,5], including intracerebral hemorrhage and subarachnoid hemorrhage (SAH); both may require emergent neurosurgical management. Perioperative management of these patients is further complicated by cocaine-associated cardiac and neurologic effects and is the focus of this review. These cardiac effects include myocardial infarction (MI) ischemia, dysrhythmias, and cardiomyopathy; while the neurological effects include seizures, cerebral hemorrhage, ischemia, and infarction. These perioperative cocaine-associated complications demand special considerations due to the complex pharmacological interactions with cocaine. This review was motivated by the presentation of a patient with SAH complicated by cocaine with a synopsis of that case briefly presented.

\section{Background}

A 48 year-old, $47 \mathrm{~kg}$ female presented with a sudden onset of headache, lower extremity weakness and seizures. The patient initially presented to an outside hospital where her depressed mental status required endotracheal intubation.
Her past medical history was pertinent for migraine headaches, cocaine abuse, hyperlipidemia, and cigarette smoking. She was transferred to our tertiary referral center for definitive management.

Admission laboratory abnormalities included an elevated blood glucose $(207 \mathrm{mg} / \mathrm{dL})$ and troponin I level $(0.48 \mathrm{ng} / \mathrm{ml})$; urine toxicology revealed cocaine and benzodiazepines. Cocaine ingestion was estimated to be approximately 2 hours prior to toxicology screening.

Electrocardiograph (EKG) revealed a sinus tachycardia (108/min) with $2 \mathrm{~mm}$ ST depression in leads V4-6. An urgent echocardiogram revealed severe anterior-septal wall hypokinesis with an estimated ejection fraction of $45-50 \%$. The patient received two boluses of midazolam (2-4 mg) for sedation following admission for agitation related to her cocaine usage and insulin for treatment of hyperglycemia. Treatment of hydrocephalus required ventriculostomy insertion with the ventriculostomy remaining open to allow cerebrospinal fluid drainage. Intracranial pressure was monitored intraoperatively with no episodes of intracranial hypertension. An arterial catheter was placed for hemodynamic monitoring; a right internal jugular central venous catheter was placed for access. A nitroprusside infusion was begun to maintain systolic blood pressure less than $140 \mathrm{mmHg}$ as intracranial pressure was zero with an open cranium. A combination of midazolam and isoflurane was administered for general anesthesia for emergent 
Dwarakanath et al. Journal of Anesthesiology and Clinical Science 2013, http://www.hoajonline.com/journals/pdf/2049-9752-2-12.pdf

doi: 10.7243/2049-9752-2-12

Table 1. Pharmacokinetics of cocaine and major metabolites.

\begin{tabular}{lcc}
\hline Cocaine \& Metabolites & $\begin{array}{c}\text { Approximate Onset } \\
\text { of Detectable Urine } \\
\text { Concentrations (hours) }\end{array}$ & $\begin{array}{c}\text { Approximate Duration } \\
\text { of Detectable Urine } \\
\text { Concentrations (hours) }\end{array}$ \\
\hline Cocaine & 2.4 & 16.3 \\
Benzoylecgonine & 2.1 & 54.3 \\
Ecgonine methylester & 2.1 & 44.2 \\
m-hydroxybenzoylecgonine & 5.6 & 15 \\
p-hydroxybenzoylecgonine & 3.8 & 9.5 \\
Norbenzoylecgonine & 5.1 & 18.2 \\
Ecgonine & 4.9 & 36.8 \\
\hline
\end{tabular}

cerebral angiogram. A leaking fusiform left vertebral artery aneurysm proximal to the posterior inferior cerebellar artery not amenable to endovascular coiling was identified.

A repeat troponin level elevation $(2.16 \mathrm{ng} / \mathrm{ml})$ confirmed a diagnosis of cocaine-associated non-ST elevation myocardial infarction. The recent SAH precluded further management with anticoagulants including heparin for a diagnostic/ therapeutic cardiac catheterization or surgical revascularization. Neurosurgery proceeded to craniotomy for emergent aneurysm clipping recognizing the increased cardiac risks. The patient received additional midazolam with anesthesia maintained with isoflurane and a sufentanil infusion $(0.5 \mathrm{mcg} / \mathrm{kg} / \mathrm{min})$. A left subclavian pulmonary artery catheter was placed at the start of the case to monitor the hemodynamic responses to vasoactive medications with recent cocaine use and a cocaineassociated myocardial infarction. If temporary clipping was required intraoperatively a the pulmonary artery would allow for monitoring of cardiac indices to see if neuroprotective medications could be safely administered. Normal saline was administered following pulmonary artery pressures to optimize cardiac output. A pulmonary artery catheter was chosen to allow for postoperative monitoring in the intensive care unit of cardiac parameters. Temperature was carefully maintained to avoid hyperthermia induced increases in $\mathrm{CMRO}_{2}$.

The goal for intraoperative cerebral perfusion pressure was $60 \mathrm{mmHg}$ with a systolic blood pressure of less than $140 \mathrm{mmHg}$. This was achieved with a labetalol infusion and nitroglycerine with nitroprusside readily available if required. The permanent clip was placed without a temporary clip. After clipping, the labetalol dose was lowered to improve cerebral perfusion pressure. Calcium chloride (1 gram) and sodium bicarbonate (50 mEq) were administered to enhance inotropy.

The patient's postoperative course in the neurosurgical intensive care unit was complicated by pneumonia requiring antibiotics following a suspected aspiration before admission with a $\mathrm{PaO}_{2}$ of $195 \mathrm{mmHg}$ receiving $100 \%$ oxygen. The patient had a worsening neurological status requiring urgent angioplasty for cerebral vasospasm on hospital day. Prior to transfer to a rehabilitation facility, a cardiac catheterization was performed revealing coronary artery disease with luminal occlusion as follows: $60 \%$ diagonal branch of the left anterior descending, $30 \%$ of the right coronary, and $20 \%$ left main disease. Left ventricular systolic wall motion function was normal with an overall ejection fraction of $65 \%$. Risk factor modification was recommended.

\section{Discussion \\ General cocaine}

Cocaine (benzoylmethylecgonine) is an alkaloid extracted from the leaf of Erythroxylon coca bush. Cocaine inhibits transport of norepinephrine, dopamine and serotonin [6]. By blocking reuptake of endogenously released catecholamines in the sympathetic pre-synaptic receptors, catecholamines accumulate at the postsynaptic receptor causing a sympathomimetic effect. The result is increases in systolic, diastolic and mean arterial blood pressure, heart rate, and body temperature following cocaine use.

Cocaine is highly lipophilic and thus crosses the blood brain barrier rapidly. Although its metabolites, ecgonine methyl ester and benzoylecgonine, do not significantly cross the blood brain barrier, these metabolic by-products also have systemic pharmacologic effects. When cocaine is metabolized in the presence of ethanol, a metabolite cocaethylene is produced which crosses the blood brain barrier rapidly producing effects similar to cocaine [7]. Cocaine metabolites have a delayed production as compared to the parent compound, but may persist in detectable concentrations for over 2 days (Table 1). As such, clinicians should expect that symptoms of cocaine exposure may be prolonged in some individuals and the occurrence of withdrawal symptoms may be delayed becoming several days after exposure.

\section{Polysubstance abuse: cocaine interactions with tobacco and alcohol}

Polysubstance abuse is common with cocaine as cocaine is often "cut" with amphetamines. Ethanol prolongs cocaine's euphoric effects and thus its use is common with cocaine [6]. The combination of ethanol and cocaine has higher morbidity and mortality [8] rates than either substance alone. This is due in part to the metabolite produced, cocaethylene, which readily blocks dopamine reuptake. Cocaethylene has been associated with a 40 times increase in cardiac acute events and 22 times increase in sudden death [9]. Ethanol administration with cocaine enhances cardiac depression producing more severe cardiomyopathies than either cocaine or ethanol alone [10]. In our case, the toxicology did not reveal recent alcohol intake.

Concomitant use of cocaine with tobacco also has adverse and synergistic effects. Cigarette smoking exacerbates adrenergic-mediated effects of cocaine by increasing myocardial oxygen demand, heart rate and systemic arterial pressure while narrowing the diameter of the diseased coronary artery thus reducing myocardial oxygen supply [11]. In our case, the patient was at higher risk for these effects with her tobacco usage history. 
Table 2. Recommendations of the American Heart Association (AHA) for the treatment of cocaine-related myocardial ischemia or infarction ${ }^{[14]}$.

\begin{tabular}{l}
\hline Class IB \\
Benzodiazepines \\
Aspirin \\
Nitroglycerine \\
\hline Class IIB \\
Calcium Channel Blocker \\
Phentolamine \\
\hline
\end{tabular}

\section{Cardiac}

Cocaine intake predisposes users to numerous cardiovascular complications including hypertension, myocardial ischemia and infarction, cardiomyopathy, dysrhythmias and endocarditis [12]. Cocaine's inhibition of norepinephrine and dopamine reuptake at presynaptic adrenergic terminals creates a state of catecholamine excess leading to dose-dependent increases in heart rate, blood pressure, and cardiac contractility [13]. Prevention of elevated blood pressure following $\mathrm{SAH}$ can be crucial to prevent $\mathrm{SAH}$ re-bleeding. Antagonizing the $\beta$-adrenergic receptors without a-adrenergic receptor blockade can produce an unopposed a-adrenergic effect thus increasing blood pressure and worsening coronary vasoconstriction [14]. Although the selective $\beta 1$ antagonist metoprolol has not been studied in cocaine-associated chest pain, its shortacting counterpart, esmolol, significantly increases blood pressure in up to $25 \%$ of patients [15]. Labetalol has been proposed to control the pressor response of cocaine. Labetalol reduces the pressor response to cocaine in humans, but not the coronary vasoconstriction, possibly due to $\beta$-adrenergic effects predominating at those doses [12]. Calcium channel antagonists (nicardipine, nimodipine, nifedipine) have been effective in reducing the pressor response to cocaine [16]. Nitrovasodilators such as nitroprusside and nitroglycerine can be used for hypertensive management by reducing the workload of the heart and promoting recovery of cardiac function however the potential side effect of increased intracranial pressure with a SAH and closed cranium may limit nitrovasodilator usage. Additional benefits of nitroglycerin may include reversal of cocaine-associated vasoconstriction that has been shown during cardiac catheterization [17].

Cocaine increases myocardial oxygen demand, concomitantly decreasing myocardial oxygen supply via a-adrenergic mediated vasoconstriction. Cocaine-mediated effects include release of endothelin-1 and decreased production of nitric oxide [12]. Cocaine via increased norepinephrine levels induces coronary artery spasm causing coronary ischemia and cardiac arrhythmias [14]. Cocaine causes structural defects in the endothelial-cell barrier increasing permeability to low-density lipoprotein [18] and enhancing expression of endothelial adhesion molecules and leukocyte migration [19]; this leads to progression of atherosclerosis [14]. Thus, cocaine abusers often have accelerated coronary atherosclerosis with coronary angiograms performed for cocaine-associated chest pain revealing obstructive atherosclerotic disease in 35\% to $55 \%$ of patients [20]. The risk of acute $\mathrm{MI}$ is increased with cocaine users compared to age-matched controls [21]. Cocaine is rapidly metabolized to ecgonine methyl ester and benzoylecgonine; however these metabolites also cause coronary artery vasoconstriction, which in turn leads to delayed/recurrent myocardial ischemia or infarction several hours after cocaine ingestion [22].

Abnormal EKGs occur in $56-84 \%$ of patients with cocaineassociated chest pain however EKG sensitivity for predicting $\mathrm{MI}$ is low at 36\% [23]. Cardiac troponins are more sensitive and specific markers for cocaine-associated MI than EKG changes [24]. In our case, the EKG did reveal nonspecific ST depression. On admission, the initial troponin was elevated and continued to rise, suggestive of a non-ST segment myocardial infarction. An urgent echocardiogram was performed as its results could alter treatment strategies. With recent $\mathrm{SAH}$ and craniotomy in our case, anticoagulation was contraindicated precluding coronary angiogram and antiplatelet therapies.

In our case, the fact that the patient was admitted with SAH may have also contributed to some of the cardiac manifestations, particularly the elevations in troponin I concentration and EKG changes. Cardiac sequelae from SAH have been well described and may parallel many of the problems seen after cocaine ingestion. Troponin I elevation and QT prolongation are common to $\mathrm{SAH}$, as are T-wave inversion and ST-segment elevation. Chest pain may occur as well, in the few patients who actually experience myocardial infarction. SAH may present with hyperdynamic left ventricular function or 'myocardial stunning' (so called tako-tsubo syndrome) [25]. Cardiac dysfunction after both cocaine ingestion and SAH is typically transient, but depending on the clinical status of the patient, also potentially deleterious. Clinicians should have a high index of suspicion for cardiac dysfunction in patients who suffer from SAH after cocaine ingestion due to their additive, and possibly synergistic, cardiac sequelae.

The American Heart Association (AHA) recommendations emphasize different treatment strategies are required for patients with cocaine-associated MI or unstable angina than from other causes of acute coronary syndrome [26]. (Table 2) With cocaine-associated chest pain, benzodiazepines have beneficial cardiac hemodynamic effects [27] and should be used early. In animal models, benzodiazepines decrease the central stimulatory effects of cocaine indirectly reducing cardiovascular toxicity [14]. Midazolam was chosen as the perioperative benzodiazepine for administration in our case.

Other treatment strategies for the effects of cocaineassociated cardiac effects include vasodilators and those with adrenergic effects. Nitroglycerin relieves cocaineassociated chest pain and can be used in combination with a benzodiazepine [27]. The a-antagonist effect of phentolamine has been effective to treat cocaine-associated 
Dwarakanath et al. Journal of Anesthesiology and Clinical Science 2013,

Table 3. Pertinent commonly used drugs that can prolong QT interval.

\begin{tabular}{l}
\hline Anti-emetics \\
Ondansetron \\
Dolasetron \\
\hline Antibiotics \\
Ciprofloxacin \\
Levofloxacin \\
\hline Anti-arrhythmics \\
Amiodarone \\
Procainamide \\
Sotalol \\
Quinidine \\
\hline Phenothiazines/Antisychotics \\
Haloperidol \\
Droperidol \\
Chlorpromazine \\
Methadone
\end{tabular}

acute coronary syndrome by relieving cocaine-associated coronary vasoconstriction [14]. $\beta$-blockers, one of the main therapies of acute coronary syndrome, is contraindicated with cocaine-associated myocardial ischemia secondary to the unopposed vasoconstrictive alpha effects of cocaine.

Cocaine predisposes patients to intracoronary thrombus formation by increasing platelet activation and aggregability $[18,19]$ and plasminogen-activator inhibitor [19]. To prevent this complication, the AHA recommends aspirin and unfractionated heparin or low molecular weight heparin for patients with cocaine-associated MI unless contraindicated [14]. These were contraindicated in our case due to a recent $\mathrm{SAH}$ requiring a craniotomy. Because of the risk of cocaine-associated cerebral events including intracranial hemorrhage, the AHA reserves fibrinolytic therapy for patients with angiographic coronary artery occlusion who are not candidates for percutaneous coronary intervention [14]. Cocaine use predisposes to cardiac arrhythmias including sinus tachycardia, sinus bradycardia, supraventricular arrhythmias, ventricular tachycardia, ventricular fibrillation, Torsades de pointes and asystole. Cocaine's sympathomimetic effects increase ventricular irritability and lower the ventricular fibrillation threshold. Similar to the actions of Class I antiarrhythmic agents, cocaine blocks sodium channels, which can inhibit generation and conduction of action potentials prolonging QRS and QT intervals [28]. Cocaine increases intracellular calcium that may also cause ventricular arrhythmias [29]. The life threatening arrhythmias associated with cocaine occurs with concomitant myocardial damage and hemodynamic instability. Treatment of arrhythmias requires correction of any metabolic abnormalities in conjunction with appropriate antiarrhythmic agents. Therapy for cocaine-associated QRS and QT prolongation includes administration of sodium bicarbonate to antagonize sodium channel blockade (QRS and QTc prolongation) [28]. Antiarrhythmic Class IA medications should be avoided since they may exacerbate prolongation of QRS and QT intervals. Within the Class IA antiarrhythmics lidocaine potentially has cerebral protective effects [30].
Lidocaine has been safely used in a small number of patients with cocaine-induced ventricular tachycardia and fibrillation [30] and was considered weighing the risks of Torsades de pointes and seizure in this particular patient as lidocaine may lower the seizure threshold [31]. The use of amiodarone for ventricular arrhythmias with recent cocaine ingestion has not been well defined [14].

Prolongation of the QT interval is common after SAH without recent cocaine use and may also occur with cocaine use. With QT interval prolongation, drugs that could prolong QT intervals perioperatively (Table 3 ) should be avoided to prevent Torsades de Pointes. Volatile agents in the presence of excess catecholamines may further sensitize the myocardium to arrhythmias and should be used cautiously in patients with recent cocaine use. In our case, the patient did not exhibit QT prolongation or ventricular arrhythmias; isoflurane was able to be used.

Cardiac complications associated with long-term cocaine abuse include chronic left ventricular systolic dysfunction and cardiomyopathy [32]. Dilated cardiomyopathy may be attributed to cocaine's direct toxic effect causing myofibrils destruction and interstitial fibrosis [33]. The hyperadrenergic state induced by cocaine may lead to subendocardial contraction band necrosis, myocarditis, or endocarditis $[32,33]$. These cardiac complications of chronic cocaine abuse can result in further preoperative cardiac evaluation to assess myocardial dysfunction impacting intraoperative monitoring of cardiac function (e.g. pulmonary artery catheter or transesophageal echocardiogram) and altering anesthetic technique. Further echocardiographic evaluation in our case identified anterior-septal wall hypokinesis, prompting the decision for pulmonary artery catheter placement for perioperative management.

\section{Neurological}

\section{Vascular abnormalities}

Cocaine use has been associated with subarachnoid and intracerebral hemorrhages with the patients frequently having preexisting neurovascular abnormalities, aneurysms and arteriovenous malformations [34,35]. In our case, the patient presented with SAH secondary to a cerebral aneurysm. Chronic cocaine use appears to predispose patients who harbor incidental neurovascular anomalies to present with intracranial hemorrhage at an earlier point in their natural history than similar non-cocaine users [35]. Rupture of these neurovascular abnormalities is likely precipitated by cocaineassociated hypertension.

Chronic cocaine use affects the initial presentation and outcome following SAH. Compared to nonusers, cocaine use predisposes aneurysms to rupture significantly earlier (33 versus 52 years of age) and at a smaller diameter (5 versus 11 $\mathrm{mm}$ ) [36]. The mechanism of cocaine-associated aneurysmal rupture most likely involves prolonged hypertensive episodes with transmission of increased blood pressure to saccular 
aneurysms [37]. Patients presenting with a SAH after cocaine use have a 4.2 times risk of a poor Hunt and Hess grade [35] with the higher Hunt and Hess grade independent of cocaine's effect on blood pressure [38]. Patients with cocaine associated SAH have been shown to have worse clinical outcomes than other SAH patients [39]. The knowledge and early recognition of the complications from cocaine use are essential for perioperative management.

Cocaine causes other central nervous system effects. These cerebral effects include intracranial hemorrhage and/ or cerebral ischemia as an underlying process secondary to cocaine abuse. Other neurologic sequelae from cocaine usage include seizures, cerebral vasoconstriction and vasospasm $[6,40,41]$. Caring for critically ill patients who have cocaine exposure can be problematic, even in patients without intracranial bleeding. Cocaine may exacerbate anxiety and potentiate delirium, which are common problems in general critical care patients. As a result, these patients often require aggressive sedation and treatment of delirium to prevent them from being harmful to themselves or their healthcare providers. Delirium treatment in the acute stages is often best accomplished by using haloperidol intravenously or intramuscularly. The risks of QTc interval prolongation may be magnified in this scenario, as both cocaine and haloperidol may increase the QTc interval. Clinicians must also be wary of withdrawal syndromes, which may present soon after the cocaine exposurure or long after, due to the persistence of the pharmacologically active metabolites.

\section{Seizures}

Cocaine use can elicit life-threatening seizures, which play a major role in cocaine-associated mortality [42]. Prompt seizure treatment can thus impact outcome with administration of benzodiazepines the initial therapy recommended. Cocaine induced seizures can be dopamine-mediated and thus resistant to medications that are GABA-mediated or act on sodium or calcium channels. Under these circumstances, seizures may be refractory to traditional anticonvulsants (e.g. benzodiazepines, barbiturates, phenytoin, and inhalational agents). The role of newer anticonvulsants such as levetiracetam and lacosamide is not well defined. One therapeutic option is dexmedetomidine, which may inhibit dopamine-mediated cocaine side effects, and in standard sedation doses has been shown to increase the seizure threshold in rats [43]. This action may be beneficial to inhibit dopamine-related cocaine events such as seizures, in addition to the potentially beneficial sedative effects. Medications used to treat some of the cardiovascular cocaine-associated complications can exacerbate seizures and may include lidocaine [44], calcium channel blockers [45], $\beta$-adrenergic antagonists, [46] and labetalol [47].

\section{Cerebral hypoperfusion}

Cocaine associated cerebral ischemia is most likely multifactorial involving cerebral vasospasm, platelet aggregation, thrombus formation, and vasculature changes that impair oxygenation.

\section{Anesthetic management}

Specific considerations for anesthetic management following recent cocaine-use include management to prevent hypertension including preoperative sedation, appropriate monitoring, and hemodynamic goals. Additional considerations include potential pseudocholinesterase deficiency secondary to cocaine metabolism and implications of chronic cocaine abuse.

\section{Premedication and sedation}

Benzodiazepines can reduce cocaine-associated hemodynamic changes, and prevent myocardial ischemia and seizures, while concomitantly providing anxiolysis and sedation. Dexmedetomidine, an a-2 agonist with sympatholytic effects, may also provide additional sedative and analgesic benefits. In healthy subjects naïve to cocaine [39], dexmedetomidine prevented increases in heart rate, skin resistance and sympathetic nervous system activity following intranasal cocaine administration. These properties of dexmedetomidine may be advantageous to counteract cocaine's sympathomimetic cardiovascular effects.

\section{Hemodynamic management}

Preoperative prevention of hypertension to prevent additional $\mathrm{SAH}$ is critical prior to cerebral aneurysm definitive therapy with the detailed effects of these drugs covered earlier in this review. In our case, we chose to use labetalol initially for hypertensive management in combination with a benzodiazepine, midazolam with titration and monitoring; our patient was responsive to this combination. The concomitant use of midazolam with the labetalol probably helped attenuate a sympathetic response. Other therapeutic options for cocaine-associated hypertension can include nitroprusside, nitroglycerine, and calcium channel antagonists. Cardioselective beta-blockers, such as metoprolol or esmolol, should be avoided in this acute period. Maintenance of cardiovascular stability is also important during endovascular coiling (although coiling was not successful in our case) and clipping of an aneurysm. In our case with a cocaineassociated $\mathrm{Ml}$, we chose to use a pulmonary artery catheter for monitoring with other potential monitoring options including stroke volume variation, pulse pressure variation, or transesophageal echocardiography.

\section{Pseudocholinesterase deficiency}

Butyrylcholinesterase (pseudocholinesterase) is the major detoxicating enzyme of cocaine [48] and is important for metabolizing succinylcholine. With succinylcholine and cocaine both substrates for pseudocholinesterase, a prolonged neuromuscular block can occur in a cocaine-abusing patient presumably secondary to pseudocholinesterase depletion 
during cocaine metabolism [49]. Although prolonged blockade is a potential risk, succinylcholine in standard doses has been used when cocaine-abusing parturients required a rapid sequence induction [49].

\section{Chronic cocaine abuse}

The data concerning anesthetic management of patients undergoing emergency surgery with cocaine intoxication is sparse. A majority of the literature has focused on cocaineabusing parturients $[\mathbf{5 0 , 5 1 ]}$. Our patient presented for emergent intervention of a bleeding cerebral aneurysm with cocaineassociated cardiovascular and neurovascular complications. No other reports could be located in PubMed for management during the perioperative period (preoperative, intraoperative, and postoperative) of cocaine abuser presenting with a cerebral aneurysm.

\section{Postoperative cerebral vasospasm}

Cocaine users compared to nonusers observed following $\mathrm{SAH}$ present with poorer Hunt and Hess classification and a 2.8 times greater risk of subsequent cerebral vasospasm [36]. Cocaine has a short serum half-life, and although its initial serum associated cerebral vasoconstriction may be short lived, cocaine with its high lipophilic properties, crosses the blood brain barrier. Cocaine and its metabolites remain significantly longer in the brain than in the blood with the primary metabolite, benzoylecgonine having a slower clearance and more potent vasoconstriction than cocaine [51]. Benzoylecgonine has been found in the brain tissue up to 22 days following the last cocaine use [52] and thus can occur exacerbate cerebral vasospasm. Due to the persistence of pharmacologically active metabolites, cocaine withdrawal syndromes may present during the period of cerebral vasospasm potentially complicating diagnosis and management.

Prevention of cerebral vasospasm in the setting of SAH associated with cocaine is not well studied. Conventional prophylaxis of cerebral vasospasm after aneurysmal SAH involves routine administration of nimodipine. Dihydropyridine calcium channel blockers appear to have some beneficial effect on cerebral blood flow and may limit ischemia after cocaine use [53], though no clear evidence suggests a specific agent of choice. Nimodipine may be problematic in some patients after cocaine-associated SAH due to the erratic absorption and systemic blood pressure effects, as well as the high cost of the 21-day regimen. As always, use of antihypertensive agents such as dihydropyridine calcium channel blockers must be weighed with the risk of excessively lowering blood pressure in the setting of cerebral vasospasm.

\section{Conclusion}

Cocaine-induced hypertension can lead to cerebral aneurysm rupture and intracranial hemorrhage with a preexisting neurovascular abnormality. These may require expectant surgical management resulting in the perioperative care of these patients including anesthetic management following recent cocaine intake. In our case, a woman with a history of cocaine abuse and recent cocaine usage presented with a SAH. Her course was complicated by a cocaine-associated myocardial infarction. Initial attempts to emergently secure the aneurysm with an endovascular approach were unsuccessful with aneurysm clipping successful. The perioperative course was complicated by cerebral vasospasm requiring treatment with cerebral artery angioplasty and development of pneumonia.

Specific preoperative management strategies for cocaineassociated myocardial and cerebral effects and specific anesthetic considerations have been reviewed. Patients may present for emergent neurosurgical management following acute cocaine intake which can be further complicated by long term implications due to chronic cocaine abuse. These circumstances can require hemodynamic management of cocaine-associated coronary and cerebral vasoconstriction and treatment of other cocaine-related complications including but not limited to seizures. Cerebral vasospasm can be potentially exacerbated by longer acting and more potent vasoconstrictive cocaine metabolites. This review summarizes the perioperative management of a case of lifethreatening complications related to recent cocaine intake and chronic complications due to cocaine abuse.

\section{Competing interests}

The authors declare that they have no competing interests.

Publication history

Received: 19-Dec-2012 Revised: 24-Jan-2013

Re-Revised: 29-Jan-2013 Accepted: 31-Jan-2013

Published: 15-Feb-2013

\section{References}

1. Substance Abuse and Mental Health Services Administration, Office of Applied Studies. Drug Abuse Warning Network, 2009: National Estimates of Drug-Related Emergency Department Visits. DAWN Series D-35, DHHS Publication No. (SMA) 11-4659. Rockville, Md: Substance Abuse and Mental Health Services Administration, Office of Applied Studies; 2011.

2. Afonso L, Mohammad T and Thatai D: Crack whips the heart: a review of the cardiovascular toxicity of cocaine. Am J Cardiol 2007, 100:10403. I Article | PubMed

3. United Nations Office on Drugs and Crime (UNODC). 2012 World Drug Report. Slovakia: United Nations Publications; 2012

4. Martin-Schild S, Albright KC, Hallevi H, Barreto AD, Philip M, Misra V, Grotta JC and Savitz SI: Intracerebral hemorrhage in cocaine users. Stroke 2010, 41:680-4. | Article | PubMed Abstract | PubMed Full Text

5. Mangiardi JR, Daras M, Geller ME, Weitzner I and Tuchman AJ: Cocainerelated intracranial hemorrhage. Report of nine cases and review. Acta Neurol Scand 1988, 77:177-80. I Article I PubMed

6. Enevoldson TP: Recreational drugs and their neurologicalcnsequences. J Neurol Neurosurg Psychiatry 2004, 75 Suppl 3:iii9-15. | Article | PubMed Abstract | PubMed Full Text

7. Andrews P: Cocaethylene toxicity. J Addict Dis 1997, 16:75-84. | Article I PubMed

8. Randall $\mathrm{T}$ : Cocaine, alcohol mix in body to form even longer lasting, more lethal drug. JAMA 1992, 267:1043-4. | Article | PubMed 
9. Keegan A: Cocaine plus alcohol, a deadly mix. NIDA Notes 1991, 6: 18-9.

10. Mueller PJ, Gan Q and Knuepfer MM: Ethanol alters hemodynamic responses to cocaine in rats. Drug Alcohol Depend 1997, 48:17-24. I Article I PubMed

11. Moliterno DJ, Willard JE, Lange RA, Negus BH, Boehrer JD, Glamann DB, Landau C, Rossen JD, Winniford MD and Hillis LD: Coronary-artery vasoconstriction induced by cocaine, cigarette smoking, or both. $N$ Engl J Med 1994, 330:454-9. | Article | PubMed

12. Lange RA and Hillis LD: Cardiovascular complications of cocaine use. $N$ Engl J Med 2001, 345:351-8. I Article I PubMed

13. Foltin RW, Ward AS, Haney M, Hart CL and Collins ED: The effects of escalating doses of smoked cocaine in humans. Drug Alcohol Depend 2003, 70:149-57. I Article I PubMed

14. McCord J, Jneid H, Hollander JE, de Lemos JA, Cercek B, Hsue P, Gibler WB, Ohman EM, Drew B, Philippides G and Newby LK: Management of cocaine-associated chest pain and myocardial infarction: a scientific statement from the American Heart Association Acute Cardiac Care Committee of the Council on Clinical Cardiology. Circulation 2008, 117:1897-907. | Article | PubMed

15. Sand IC, Brody SL, Wrenn KD and Slovis CM: Experience with esmolol for the treatment of cocaine-associated cardiovascular complications. Am J Emerg Med 1991, 9:161-3 3. | Article | PubMed

16. Knuepfer MM: Cardiovascular disorders associated with cocaine use: myths and truths. Pharmacol Ther 2003, 97:181-222. | $\underline{\text { Article | PubMed }}$

17. Brogan WC, 3rd, Lange RA, Kim AS, Moliterno DJ and Hillis LD: Alleviation of cocaine-induced coronary vasoconstriction by nitroglycerin. J Am Coll Cardiol 1991, 18:581-6. I Article I PubMed

18. Minor RL, Jr., Scott BD, Brown DD and Winniford MD: Cocaine-induced myocardial infarction in patients with normal coronary arteries. Ann Intern Med 1991, 115:797-806. I Article I PubMed

19. Moliterno DJ, Lange RA, Gerard RD, Willard JE, Lackner C and Hillis LD: Influence of intranasal cocaine on plasma constituents associated with endogenous thrombosis and thrombolysis. Am J Med 1994, 96:492-6. I Article I PubMed

20. Dressler FA, Malekzadeh S and Roberts WC: Quantitative analysis of amounts of coronary arterial narrowing in cocaine addicts. Am J Cardiol 1990, 65:303-8. I Article I PubMed

21. Mittleman MA, Mintzer D, Maclure M, Tofler GH, Sherwood JB and Muller JE: Triggering of myocardial infarction by cocaine. Circulation 1999, 99:2737-41. | Article | PubMed

22. Brogan WC, 3rd, Lange RA, Glamann DB and Hillis LD: Recurrent coronary vasoconstriction caused by intranasal cocaine: possible role for metabolites. Ann Intern Med 1992, 116:556-61. I Article I PubMed

23. Hollander JE, Hoffman RS, Gennis P, Fairweather P, DiSano MJ, Schumb DA, Feldman JA, Fish SS, Dyer S, Wax P and et al.: Prospective multicenter evaluation of cocaine-associated chest pain. Cocaine Associated Chest Pain (COCHPA) Study Group. Acad Emerg Med 1994, 1:330-9. I Article I PubMed

24. Hollander JE, Levitt MA, Young GP, Briglia E, Wetli CV and Gawad Y: Effect of recent cocaine use on the specificity of cardiac markers for diagnosis of acute myocardial infarction. Am Heart J 1998, 135:245-52. | Article | PubMed

25. Hessel EA $2^{\text {nd }}$ : The brain and the heart. Anesth Analg 2006, 103: 522-6. I Article

26. Baumann BM, Perrone J, Hornig SE, Shofer FS and Hollander JE: Randomized, double-blind, placebo-controlled trial of diazepam, nitroglycerin, or both for treatment of patients with potential cocaineassociated acute coronary syndromes. Acad Emerg Med 2000, 7:878-85. | Article | PubMed

27. Honderick T, Williams D, Seaberg D and Wears R: A prospective, randomized, controlled trial of benzodiazepines and nitroglycerine or nitroglycerine alone in the treatment of cocaine-associated acute coronary syndromes. Am J Emerg Med 2003, 21:39-42. | Article | PubMed

28. Beckman KJ, Parker RB, Hariman RJ, Gallastegui JL, Javaid JI and Bauman $\mathrm{JL}$ : Hemodynamic and electrophysiological actions of cocaine. Effects of sodium bicarbonate as an antidote in dogs. Circulation 1991, 83:1799-
807. | Article | PubMed

29. Billman GE: Effect of calcium channel antagonists on cocaine-induced malignant arrhythmias: protection against ventricular fibrillation. J Pharmacol Exp Ther 1993, 266:407-16. | Article | PubMed

30. Popp SS, Lei B, Kelemen E, Fenton AA, Cottrell JE and Kass IS: Intravenous antiarrhythmic doses of lidocaine increase the survival rate of CA1 neurons and improve cognitive outcome after transient global cerebral ischemia in rats. Neuroscience 2011, 192:537-49. I Article I PubMed

31. Shih RD, Hollander JE, Burstein JL, Nelson LS, Hoffman RS and Quick AM: Clinical safety of lidocaine in patients with cocaine-associated myocardial infarction. Ann Emerg Med 1995, 26:702-6. | Article | PubMed

32. Egred M and Davis GK: Cocaine and the heart. Postgrad Med J 2005, 81:568-71. | Article | PubMed Abstract | PubMed Full Text

33. Virmani R, Robinowitz M, Smialek JE and Smyth DF: Cardiovascular effects of cocaine: an autopsy study of $\mathbf{4 0}$ patients. Am Heart J 1988, 115:1068-76. | Article | PubMed

34. Pozzi M, Roccatagliata D and Sterzi R: Drug abuse and intracranial hemorrhage. Neurol Sci 2008, 29 Suppl 2:S269-70. I Article I PubMed

35. Fessler RD, Esshaki CM, Stankewitz RC, Johnson RR and Diaz FG: The neurovascular complications of cocaine. Surg Neurol 1997, 47:339-45. I Article I PubMed

36. Vannemreddy P, Caldito G, Willis B and Nanda A: Influence of cocaine on ruptured intracranial aneurysms: a case control study of poor prognostic indicators. J Neurosurg 2008, 108:470-6. I Article I PubMed

37. Howington JU, Kutz SC, Wilding GE and Awasthi D: Cocaine use as a predictor of outcome in aneurysmal subarachnoid hemorrhage. $J$ Neurosurg 2003, 99:271-5. I Article I PubMed

38. Simpson RK, Jr., Fischer DK, Narayan RK, Cech DA and Robertson CS: Intravenous cocaine abuse and subarachnoid haemorrhage: effect on outcome. Br J Neurosurg 1990, 4:27-30. | Article | PubMed

39. Menon DV, Wang Z, Fadel PJ, Arbique D, Leonard D, Li JL, Victor RG and Vongpatanasin W: Central sympatholysis as a novel countermeasure for cocaine-induced sympathetic activation and vasoconstriction in humans. J Am Coll Cardiol 2007, 50:626-33. I Article I PubMed

40. Madden JA and Powers RH: Effect of cocaine and cocaine metabolites

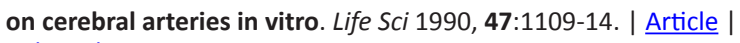
PubMed

41. Strickland TL, Mena I, Villanueva-Meyer J, Miller BL, Cummings $\mathrm{J}$, Mehringer $\mathrm{CM}$, Satz $\mathrm{P}$ and Myers $\mathrm{H}$ : Cerebral perfusion and neuropsychological consequences of chronic cocaine use. $J$ Neuropsychiatry Clin Neurosci 1993, 5:419-27. I Article I PubMed

42. Spivey WH and Euerle B: Neurologic complications of cocaine abuse. Ann Emerg Med 1990, 19:1422-8. I Article I PubMed

43. Whittington RA, Virag L, Vulliemoz Y, Cooper TB and Morishima HO: Dexmedetomidine increases the cocaine seizure threshold in rats. Anesthesiology 2002, 97:693-700. | Article | PubMed

44. Derlet RW, Albertson TE and Tharratt RS: Lidocaine potentiation of cocaine toxicity. Ann Emerg Med 1991, 20:135-8. I Article I PubMed

45. Derlet RW and Albertson TE: Potentiation of cocaine toxicity with calcium channel blockers. Am J Emerg Med 1989, 7:464-8. | Article | PubMed

46. Smith M, Garner D and Niemann JT: Pharmacologic interventions after an LD50 cocaine insult in a chronically instrumented rat model: are beta-blockers contraindicated? Ann Emerg Med 1991, 20:768-71. | Article I PubMed

47. Sybertz EJ, Sabin CS, Pula KK, Vliet GV, Glennon J, Gold EH and Baum T: Alpha and beta adrenoceptor blocking properties of labetalol and its R,R-isomer, SCH 19927. J Pharmacol Exp Ther 1981, 218:435-43. I Article I PubMed

48. Xie W, Altamirano CV, Bartels CF, Speirs RJ, Cashman JR and Lockridge $O$ : An improved cocaine hydrolase: the A328Y mutant of human butyrylcholinesterase is 4-fold more efficient. Mol Pharmacol 1999, 55:83-91. I Article I PubMed

49. Jatlow P, Barash PG, Van Dyke C, Radding J and Byck R: Cocaine and succinylcholine sensitivity: a new caution. Anesth Analg 1979, 58:235-8. 
Dwarakanath et al. Journal of Anesthesiology and Clinical Science 2013,

| Article | PubMed

50. Kuczkowski KM: Peripartum care of the cocaine-abusing parturient: are we ready? Acta Obstet Gynecol Scand 2005, 84:108-16. | Article | PubMed

51. Fajemirokun-Odudeyi $O$ and Lindow SW: Obstetric implications of cocaine use in pregnancy: a literature review. Eur J Obstet Gynecol Reprod Biol 2004, 112:2-8. | Article | PubMed

52. Weiss RD and Gawin FH: Protracted elimination of cocaine metabolites in long-term high-dose cocaine abusers. Am J Med 1988, 85:879-80. | Article | PubMed

53. Johnson BA, Devous MD, Sr., Ruiz P and Ait-Daoud N: Treatment advances for cocaine-induced ischemic stroke: focus on dihydropyridine-class calcium channel antagonists. Am J Psychiatry 2001, 158:1191-8. | Article | PubMed

\section{Citation:}

Dwarakanath S, Cook A M and Fahy B G: Perioperative care of the cocaine-dependent neurosurgical patient. journal of Anesthesiology and Clinical Science 2013, 2:12. http://dx.doi.org/10.7243/2049-9752-2-12 